\title{
Youth Transformation with a Focus on Asia: A Sociological Appraisal
}

\author{
Mohammad Taghi Sheykhi* \\ Professor Emeritus of Sociology, Alzahra University, Tehran, Iran \\ *Corresponding author: Mohammad Taghi Sheykhi, Professor Emeritus of Sociology, Alzahra University, Tehran, Iran
}

\section{ARTICLE INFO ABSTRACT}

Received: 蔧 May 11, 2021

Published: 幽 May 25, 2021

Citation: Mohammad Taghi Sheykhi. Youth Transformation with a Focus on Asia: A Sociological Appraisal. Biomed J Sci \& Tech Res 36(1)-2021. BJSTR. MS.ID.005797.

Keywords: Transformation; Technologies; Attractions; The Youth; Transitional Rights
The present article sociologically analyzes how the youth transformation with respect to disorders are faced in modern age. The youth are highly facing new technologies, especially in expanding urban areas. In many cases the youth have to confront unemployment because of mechanization of productions, and the shortage of income emerged, that lead to various social and economic issues within the youth. While urban attractions are rapidly increasing, and youth migration from rural to urban areas happening, a complex of new disorders are created among the young people in search of economic security. When the needs and expectations of such people are not met, they lead to neurological issues and disorders. The speed of change leading to recognizable issues within the youth, is expanding due to increasing science and technology. Electronical development has even worsened the situation. Different assumptions define young people in different countries in terms of the average age of "transitional rights" such as marriage, parenthood, employment, or even voting rights. However, young people always try to show themselves different from the previous generation. Tools such as language, music, clothing, and the like have played an effective role.

\section{Introduction}

Neurological disorders are widely observed within the young generation more because of the rapid social change occurred in recent decades. Youth cannot easily adjust with the changing conditions. Among the disorders and challenges they encounter is the neurological/ nervous system disorders [1]. While such abnormalities are widely spreading in many Asian countries, specialist doctors are not within reach for treatment [2]. That is why they mostly resort to narcotics, get into violence etc. Pain management, and performing operations usually lag behind within the youth in most societies in Asia. As estimated by WHO, neurological disorders affect as many as one billion people worldwide [3]. The current world's population surpassing 10 billion by the year 2050, will create even more neurological disorders [4].

Considering that Asia is the most populous region in the world with a population of more than 4.157 billion in the world today (WPDS: 2010), a significant proportion; This means that at least more than $25 \%$ of the continent's population is at the young age group (15-29). As far as industry, industrial development and social and cultural changes of these societies (Asian societies) are concerned, the mentioned indicators and factors have created huge changes in different dimensions for the youth. In the same way, following the changes that have taken place, young people, both boys and girls, have entered a kind of transitional stage. The departure of adolescents and young people from home, and their entry into the labor market, is a change [5]. The consequence of this transformation, which is still going on, is the generation gap and the challenges related to intergenerational relations, the challenges within the family, and symptoms of this kind. In this article, young people are examined in various forms and mainly under the influence of industrial development.

The transformation of its youth is one of the most important issues facing Asia today. At the same time, it faces a clear weakness of concept, weakness of research, and outdated policies. While the continent's young population has been growing over the last half century, there has been less relevant and practical research on youth. Similarly, the concept of youth or youth is not clearly defined and justified in terms of time. However, many of the strategies and 
policies related to youth in these societies are still not updated and are so-called classic or old. This situation has faced the youth of Asian countries with many challenges and shortcomings. One of the ways forward to achieve development is to eliminate the lack of skills and educational weaknesses among the workforce in these societies; In a way that can increase productivity. In this movement, children and adolescents are a resource to be invested in (UNICEF: 1996).

\section{Method of Research}

Methodology used in the present article is of qualitative type. In that, various paradigms have been used to find out about the facts regarding pandemics during the history. Qualitative research usually studies people, events or areas in their natural settings. In finding facts for the research, the researcher engaged in careful data collection and thoughtful analysis of what was relevant. In the documentary research applied for the present research, printed and written materials were widely regarded. The research was performed as a qualitative library-type in which the researcher had to refer to the relevant and related sources. In the current research, various documents were thoroughly investigated, and the needful inferences were made. The data fed by the investigator in the present article is hopefully reliable. Though literature on pandemics is very limited, yet the author tried to investigate many different resources in order to elicit the necessary information to build up the text.

\section{Discussion}

While the literacy index in the region has been greatly strengthened and reformed, while traditional agricultural occupations have declined, comprehensive industrial development in most parts of the continent has not been satisfactory. This situation has generally left young people in a state of uncertainty, failure to achieve new goals, and failure to meet the demands. This situation has brought with it a variety of crises, dissatisfaction and various challenges for young people. One way to alleviate this problem is to create more employment opportunities and more satisfaction among young people, both boys and girls, for the 1529 age group. The process itself requires continuous planning, adequate and comprehensive investment in various urban and rural sectors, using different industries.

Issues facing young people in terms of time and place; That is, it varies from urban to rural areas, from country to country, and even from region to region. The desires, needs, and expectations of young people are not generally the same; Rather, it differs between young people and for young people in terms of urban and rural areas, as well as in terms of how communities develop. According to Agburn, some cultural elements change faster than other cultural elements; And it affects young people in different ways. Therefore, the planning system according to the needs of the young population, the provision of appropriate facilities for them in general should be on the agenda in terms of geographical conditions and time period. In such a situation, many potential challenges among young people can be prevented. Countries such as China and India have implemented such economic, social and cultural programs and policies for their youth for many years. For example, India, in proportion to the expectations and origins of its rural population, has made sufficient investments for young people in these areas, thus providing youth satisfaction in rural areas. This measure has prevented the unwanted migration of young people to urban areas and the speed of change itself has led to the emergence of many recognizable and intergenerational issues.

Changes due to industry and technology, the consequences of the development of electronics and communications, the rapid and continuous movement of different groups of young people, especially to urban areas and larger cities, have provided challenges and new opportunities for young people. Rapid social change in recent decades has widened the usual generation gap, and in some cases even made communication between young people and previous generations or institutions difficult or even impossible [6]. On the positive side, these changes have given young people access to new technologies, new skills, a higher standard of living, more amenities, and a greater role for young people in the productivity process. This means that young people in the path of industrial development always keep the engine of industry moving, and even with their achievements, accelerate it even more. The influence of young people on industry and in contrast to their role in industrial development, has itself led to an increase in GDP for the countries and communities concerned; Increasing Gross Domestic Product (GDP) itself makes wider economic movements possible in societies.

Under such conditions, communities gain more wealth, through which they can invest more, and this in turn brings about a new cycle of production, consumption, and re-production; It means a new kind of economic and social dynamism in such societies. Therefore, young people are not only influential in this transformation, but also influential. This perspective has been experienced in the industrialized and developed countries of Western Europe since the 19th century. It is noteworthy that the wave of this change has reached the Asian region today; That is, a situation that leads to more change. Under such circumstances, urban planning authorities must provide the necessary grounds. This trend has caused intergenerational differences to be felt more than ever in the past, especially in developing societies. This means that the new generation, or young age groups, have been greatly influenced by industrial development over the last half century, and that in itself has made the views and lifestyles of young people sociologically different from those of the previous generation; It is a phenomenon that can be explored and studied. 
Within a generation, even at the same time and place, the problems of young people are different because of the specific structure of the institutions of the society in which they live, such as gender, social class, family structure, workplace, organizations within the community, and so on. The mentioned factors, or in other words, the above variables such as age, gender, etc., each play a role in creating social problems among young people. For example, the problems and demands of young people in the present age are more than in previous periods. Likewise, the expectations or demands of young people in dynamic and larger cities are higher than in smaller and less active cities. Therefore, in accordance with the temporal and spatial conditions, the demands of the young generation must be considered, and addressed. Otherwise, the complexity of the issues and the lack of response to them will create more challenges and contradictions among the youth and will prevent it from moving. It should also be noted that many factors that prevent, change, or in other words affect young people, such as gender, family, social class, workplace and the like, are inevitable.

This means that some young age groups experience more change as a result of the circumstances in which they live, while others experience less change in terms of location, social status, and family. At the same time, what is happening today, widely and apart from these variables in general, and to a large extent among young people, is the process of socialization between them. It refers to the interactions that take place between young people; Their relationship with society and each other, education between them and so on. In this article, the issues facing young people in different countries and societies are briefly examined. While youth issues, youth studies, and addressing this population in industrialized countries are more or less two centuries old, the phenomenon is for countries in the region that later have access to academic resources and research centers, and youth to cities and Industry and the like have arrived late, which has made the issue of youth development in Asia significant.

Young people in Asia are not a homogeneous group; Thus, the problems of this large population group within the Asia-Pacific region are very different from those of the developed societies of the Western world. Among other things, their social, economic and political structures are different from those of First World societies [7]. Countries like China today can be discussed and evaluated as an important source of change for young people. This situation is emerging in Iran today, and it itself requires more investment in various sectors, and the creation of more industrial and service resources; In such a way that a greater share of young people will achieve work and employment and provide an independent life. Young people themselves are the source of progress, not the issue, and globalization has greatly affected them. At the same time, young people in many developing societies have less opportunity to participate in new fields. While the policies of governments directly and indirectly affect the lives of young people, and in many cases occur unknowingly, and do not specify exactly how their daily lives today, and their future health are affected (2002). They are the factor of progress and development in any youth society, while in the case of not dealing with them properly, in some cases they are considered a problem.

Therefore, in order to make good use of this power, and to achieve greater productivity in various sectors of education, young people should be given priority. It is also worth noting that the current of globalization itself has conveyed a kind of warning and awakening to young people in various sectors. Following the process of globalization, in which many fields and information have entered different societies, the guidance and management of such information and changes that have occurred, especially among its youth, is of great importance. Otherwise, young people, while detaching themselves from the old traditions and customs of their communities, do not find their way to the new patterns and methods. The result of such conditions is the lack of progress and even in some cases the regression of the youth.

\section{Meanings and Concepts}

In order to clarify the concept of youth transformation, its different meanings can be expressed as follows:

a) Transformation from One Section to Another, for example from school to work: One of the cases of change among young people is their movement from one space, for example, the space of education to the space of work. Generally, a significant number or proportion of young people leave schools and educational institutions each year and enter employment. This is a change between them; That is, a change that affects their way of life in general. The mentioned transformation itself needs proper supervision and guidance. If young people do not have access to their favorite job after graduation (education), this will be challenging and problematic. Therefore, the creation of training courses as a bridge between education and work, itself has an effective role in the success and greater productivity of young people. This flow occurs in many cases in different countries.

b) Change within and Between A Generation, for example from youth to adulthood: This change or transformation leads to different wants, needs and conditions. Since different age groups naturally go through this evolution in a positive way, governments and planning systems must exercise due diligence and oversight. Less developed societies, which generally face the growth of a younger population, must always pay sufficient attention to the transformation from adolescence to adulthood. It is at this stage that young people, both boys and girls, need new investments such as employment, social capital, appropriate cultural capital and the like. The industry 
factor (industrial development and human development) has an effective role in this regard. In other words, as far as human development is concerned, countries should invest sufficiently in various sectors on their young generation under the age of 20 , thus preparing them for adulthood. In the absence of human development under the age of 20 , young people generally face various crises and challenges from the age of 20 onwards, which in general exposes society to a crisis and a lack of social discipline.

c) Environmental Changes: For example, changes due to migration from rural to urban areas, this in itself plays a significant role in the development of youth. Changing the geographical space from smaller environments to larger urban spaces also has an effective role in the situation of young people. Generally during this transformation, that is, migration from rural to urban areas by young people, many behavioral, personality, economic and similar changes appear between them; That is, phenomena that are less likely to occur if they do not migrate to larger (urban) areas. Therefore, development managers and planners, in the general sense, must always keep in mind the consequences of environmental change. By considering such changes, many challenges and urban ills can be controlled, and consequently a suitable urban and industrial environment can be created. Today, one of the significant and hidden problems within urban spaces is mainly due to this movement and environmental changes that go back to the evolution of young people. Therefore, the study of young people from such angles can play an effective role in the sanitation and safety of urban spaces.

A combination of the above factors and indicators has affected the lives of young people. Factors such as education, new skills, living in larger geographical areas, etc., have affected various aspects of young people's lives, both boys and girls; In such a way that, for example, the age of marriage has increased on average, and as a result, the number of children has decreased; That is, a situation that has also reduced population growth. Thus, young people, directly and indirectly under the influence of industrial development, have experienced many changes in recent decades. The combination of these changes (evolution) has caused the phenomenon of intergenerational gap or generation gap. Thus, industry, as the most important factor, influences many, and more and more, influences the attitudes and views of young people. Therefore, sociologists in general and urban and industrial sociology in particular must always clarify the consequences of these changes, so that society faces fewer contradictions. At the same time, the definition of youth age varies in different societies and in different studies; That is (10-15 years old, 15-15 years old or 10-35 years old and so on). Countries have generally defined and introduced different areas for the introduction of young age groups, in order to invest and plan accordingly. The United Nations has identified the 15-24 age group as a young population. In this topic, 15-29 years old is considered and emphasized.

\section{Hypotheses and Definitions}

Different cultural assumptions define young people in different countries in terms of the average age of "transitional rights" or their evolution, such as marriage, parenthood, employment, or voting rights. Different communities determine the age of entry into youth and the roles that young people should have in terms of entering these courses. Whereas in the past the age of entry into employment, the age of marriage, and the time of finding a parent's role began earlier, so did expectations of the younger population at a younger age. Assuming the attainment of such rights, the average age of the young population in different societies is determined. Since, following social, economic, and cultural changes, the transformation of young people into these cases occurs later, it is hypothesized that the average age of the young population is somewhat higher or higher, and that, as suggested, planning systems should Prepare young people for the mentioned courses.

Development and industry factors play an effective role in this movement. By increasing GDP through industrial development, the needs of young people can be better met. However, in many cases, little attention is paid to youth poverty; That is, eliminating this phenomenon is less of a priority for policymakers; Just thinking that young people are always moving and changing. In some cases, policymakers do not recognize that young people have high potential and can positively influence employment and incomegenerating programs for others and society as a whole [8]. There is also the hypothesis that the age and homogeneity index determine the attitudes of a group. Different individuals and social groups in different age groups have their own needs. For example, at the age of 15 , educational needs in any society should be a priority. Also, different age groups from the age of 15 and above generally need employment and livelihood. Therefore, this homogeneous group, the number and proportion of which is significant in any society, now expects to benefit from the industrial system, industrial achievements and industrial development in various sectors of agriculture, industry and other production resources. Therefore, the industrial planning system and its expansion can be responsive to the young population on the verge of entering the age of 15 and above.

Variables such as culture, class, marital status, role of parents, employment, and geographical and temporal space each in turn affect the attitudes and challenges of young people. Therefore, sociology, or in other words, social engineering, should play a good role, so that the mentioned attitudes can be organized among the youth. Young people have their own needs in each of these stages. What is more important among the mentioned cases is the variable 
of culture and class. Following the development of societies as well as the industrialization of societies, the culture of societies, or more precisely, the culture of the youth is constantly changing. This causes new classes to appear between different social groups, or to change in some way. Therefore, the planning system with the help of industrial development can meet the growing needs of young people following the cultural and class changes between them.

\section{Demographic Dimension}

The distribution of the age groups of the population also confronts the generations with power or disability in some cases. If the age groups of the young population increase, or in other words, the volume of the young population of 15-29 years old is high, the society is in danger of facing an employment crisis. Rising unemployment, falling wages, and rising food prices make young people structurally adaptable [9]. Similarly, in a situation where the structure or distribution of the population is such that more than $20 \%$ of the population is in the age group +65 years, in these circumstances, the society in some cases faces a crisis of manpower. Likewise, in the case of overproduction in one period; In Iran, for example, in the 1980s, society in the following decades faced many restrictions related to employment, livelihood, and unanswered demands of young people. Thus, monitoring the age structure of the population in a given society (in any society) ultimately lays the groundwork for socio-economic order in later years.

For example, countries such as Bangladesh, India, Indonesia, the Philippines, Vietnam, Thailand, and others that are still experiencing relatively high population growth are under pressure from young people for job demand and employment resources. In these countries, there is generally continuous and extensive cross-border migration from rural to urban areas, as well as crossborder migration between them; It happens simply to provide a livelihood and meet the basic needs of the young job-seeking population in these countries. It is noteworthy that the migration of such age groups (youth) brings with it many cases of crisis and social, economic and cultural challenges. Other countries that have experienced economic growth have also undergone population change; In a way that their birth rate has decreased dramatically. In order to prevent the employment crisis, the young population of countries should provide the ground for population change in their countries in a forward-looking way; In such a way that in the following decades, they will not face the employment crisis and high demand of young people.

Population change means bringing the two indicators of birth and mortality closer to each other, during which population growth and fertility index decrease. This situation has been going on for almost the last two decades; It happened in Iran in the 2001s. The optimistic result of such a (transformational) move is the resolution of the employment crisis in society over the coming decades.
Following the transition of the population, in such circumstances the high volume of the young population (20-39 years old, which also enters middle age, is usually indebted due to higher spending, young and the economic life of young people often becomes complex (Moolah Asia the population, aged 20-39, accounts for more than $35 \%$ of the population, or countries such as South Korea and China, where the age pyramid of the population is very narrow and long, such as Japan. Such a change in the age structure of the population necessitates that the planning system provide more opportunities for attracting young manpower in various industrial and service sectors. These countries (South Korea and China) In the previous decades and maybe until 1990, they had a large population of children and adolescents; that is, economically dependent manpower, etc., following the change of their population policies, those age groups of children and adolescents during the 2010s and ... in the ages of $39-20$ years old, i.e the age range that requires employment and continuous livelihood. Therefore, employment planning, industry and demographic policies must follow their movement in a coordinated and coherent manner.

\section{Issues Facing Young People}

The effects of globalization on young people in Asia are very clear, and for example, the youth period has also become longer. Following economic development, young people spend more time in education and training, marry later, have fewer children, and employ more women than women. These issues also create a variety of social, economic and cultural issues for young people. Therefore, following the mentioned developments, the planning system must be continuously active in policy-making and planning in different sectors, otherwise the situation of passivity and reluctance will spread among the youth. From the perspective of the previous generation, many traditional values among young people are diminished or diminished, loyalty and communication within families are affected, and so on. It is quite clear that the dynamism of society, industrial development in a society, the method of education and cultural development in a society and among young people, all cause changes in their way of life. As a result, its socio-industrial development bridges the generation gap. While this situation is inevitably emerging in most societies today, the use of appropriate measures and policies can reduce this gap as much as possible; It is a situation in which different generations can live together and with each other.

Following industrial development and globalization, social alienation (alienation) between young people and in different geographical areas is increasing. "Alienation" is itself a form of alienation that is usually measured by feelings of powerlessness, abnormality, isolation, and emptiness. According to Marx, alienation is an objective phenomenon, and following such a phenomenon, a significant proportion of young people also move to 
urban and industrial areas, and are generally employed in industry, "industrial" and service activities. This situation creates new and different cultural contexts for them; That is, a very different mental and behavioral atmosphere from the previous generation. The set of conditions generally and to a large extent leads young people to "alienation". At the same time, factors such as art, music, and other socio-cultural interactions and relationships provide the basis for this alienation among young people. This phenomenon needs to be monitored, directed and so on. Under the above conditions and compared to the previous generation, young people are more dynamic; That is, both geographically and socially. Likewise, the factors of industry and technology and the new way of life in the general sense have made those young people more and more active today; That is, the younger generation easily migrates from their homeland to a new destination. Also, with scientific, educational, skills acquisition, and the like, it moves from one situation to another and thus finds a higher and different social position.

Therefore, the planning system in countries should always expect such movements among young people. At the same time, the necessary predictions must be made about the consequences of such movements among young people. Predictions such as job opportunities, leisure opportunities, responding to more needs, consumption among young people and other new and more demands always between them Should be considered. Competition for work has increased greatly, especially in fast-growing countries. In some cases, this situation has led to unemployment for young people. In many cases, this phenomenon is even considered as a crisis among young people today. Previous areas such as literacy growth, gaining skills and expertise, raising life expectancy, etc., have created an unprecedented kind of competition among young people for employment. This trend has in some cases led to unemployment among some groups of the young population, which has left its social, cultural and psychological consequences.

The phenomenon of gender bias in some Asian societies such as India, China and Vietnam has led to the emergence of a tendency towards boys; That is, a phenomenon that has led to gender imbalance. Hence, such contexts and value and normative systems must be created in a society in such a way that gender bias gradually declines. Under such conditions, economic, industrial and social productivity, or in other words, productivity between the two sexes increases. Pre-industrialized countries and societies have greatly weakened, or largely eliminated, gender bias, or in other words, the superiority of one sex over the other. Such egalitarian thinking has led to industrial and economic growth and excellence in those societies. Hence, by considering the experiences of preindustrialized societies, balanced societies / balanced economic, industrial and social conditions can be achieved; In such a way that both sexes can use their capacities to the desired extent. This phenomenon has led to many cases of male (boys) preference in accessing education, employment and many other opportunities. This way of thinking is still present in many less developed countries; That is, the points that, following this way of thinking, provide more educational opportunities, employment, and the like for boys or men. This in itself greatly reduces the general mood and creativity of women (of the opposite sex). Hence, the achievement of opportunities in the general sense depends on the creation of equality in a society. This case is widely experienced today in industrialized countries, including Japan.

\section{Creating A New Public Space for Young People}

Young people are always trying to show themselves different from the previous generation. In this regard, various tools and techniques such as language, music, clothing and the like have played an effective role. Industrial development and the acquisition of new and diverse products have played an effective role between the new generations and the previous generations. Likewise, cultural tools and techniques in the present age have greatly and rapidly affected young people in different geographical areas. For example, in present-day Russia, contemporary China, and major countries of this type, we are witnessing vast cultural changes today. These changes mainly affect the younger generation. Therefore, and considering the above-mentioned changes, the young generation is subject to unprecedented changes. According to the mentioned changes, their planning systems should provide the necessary investments for the youth and among them. This in itself must be easily explained and accepted; That is, in a situation where there is a significant difference in the present era between the previous generation and the new generation (youth), and it is also expanding. Today's youth have created a new information space through the Internet and other new means of communication. What is remarkable is the new communication space that today is generally even run by the younger generation.

Therefore, the development of their communications, while affecting the younger generation, has been the cause of more and more changes. Given the circumstances, it is also hypothesized that young people in the coming years will have a greater and broader role in the changes caused by communication (Cyber space). This new space has caused young people to use new technology to modify their identity and create a new virtual identity for themselves. Communication spaces have played an important role in changing the identity and self-confidence of young people in recent decades. The root and source of these changes or virtual factors are communication in its various dimensions. Therefore, and given the expanding communication environment, one should always expect more changes in the way young people live. In such circumstances, and due to the changing identity among the youth, it should be possible to accept more and more young people in different sectors of industry, technology and employment in new fields with an emphasis on less developed countries. 


\section{Policies and Youth}

The challenge for governments in Asia is to identify the issues that young people face, and consequently to pursue new, targeted and appropriate policies. As Asia accounts for more than 60 percent of the world's population, the region naturally has a larger youth population than the rest of the world. Therefore, governments on the continent must pursue effective and relevant policies to prevent current challenges and potential future unrest. One of the necessary and general solutions is industrial development and creating a relationship between income and expenses of the young population in Asian countries. Countries such as China, India, Malaysia, etc. have already started such a movement. It should be noted that more countries should take steps in this direction. It is essential that governments identify the different needs of young people, and consequently pursue appropriate policies to align with the diversity of their needs. For example, education policies that affect the needs of educational content should consider the potential of young people, the priorities of individuals, and the demand of the labor market. In general, policies tailored to the needs of society, the labor market, the capacities of young people, etc., should be regulated by the relevant governments. In this way, more prosperity and satisfaction can be created among the young population.

\section{Future Research in the Field of Youth}

Although the importance of young people varies quantitatively and qualitatively in different parts of Asia, at the same time this population (youth) accounts for a large part of the relevant changes, and young people are the cause of any initiative in society; That is, socially, culturally, economically, technologically, and so on are considered; Simply because they are changeable, influential, and generally modern. In order to anticipate any change in these areas, the motivations of the younger generation must be identified. While most youth research is conducted by older researchers, it is also recommended that youth research be conducted by young age groups to address their needs and wants. In this way, more of the future challenges of the youth can be prevented. Therefore, today, the advice of youth experts is based on the fact that the authority of young people, empowering them as much as possible and involving them in decision-making should be given more attention and priority. In this way, many social challenges related to youth can be controlled [10-14].

\section{An Overview of the Changing Concepts of Youth}

While young people make up an important part of society, they did not receive enough attention until the 1960s. Until then, little research had been done on young people. Interest in studying them began in the 1960s; Simply because many student activities began in Europe from the 1960s onwards; A phenomenon that caught the attention of governments. Under these circumstances, rapid steps were taken to resolve the crisis so that the threat would not spread to the whole world. At the same time, solidarity was expressed in various ways by young people in other parts of the world, including the Asia-Pacific region; It is a kind of sympathy with the young population in European countries. Under such circumstances, governments and international organizations were forced to prioritize youth. Similarly, targeted and effective youth programs were implemented. With this move, young people have been recognized as a target group within Western governments since the 1960s; That is the move that UNESCO endorsed, and in 1978 held its first regional summit in Kathmandu, the capital of Nepal. While the United Nations designated 1989 the International Year of Youth, UNESCO launched the Asia Youth Program with three pillars:

a) Research on youth and related issues.

b) Collecting and disseminating information about youth.

c) Assisting member states in designing and formulating youth policies.

\section{Conclusion}

Young people within the same generation, and at the same time and place are different because of the specific structure of the institutions of the society in which they live such as gender, social class, family structure, workplace etc. As the time pass, transition inevitably emerge. In such a situation, the youth cannot easily adapt to the new face of life. Increasing means, and the new needs and expectations contradict leading to a gap/ vacuum for the youth. It sometimes crystallizes in the form of neurological disorders. Many youth in Asian countries are in such a situation. It is highly observed in countries like China and India. Therefore, the youth ever need to be studied and surveyed by the skilled sociologists. Many youths in modern time are left unattended. Under such a situation, and for a relief, they mostly resort to drugs and narcotics, commit violence and many more.

\section{References}

1. Atal Yogesh (2005) Youth in Asia: An Overview. Internet Retrieval.

2. Coleman James (1984) Abnormal Psychology and Modern Life $\left(7^{\text {th }}\right.$ Edn.)., New York: Pearson Scott Foresman.

3. Griffin C (2001) Imagining New Narratives of Youth: Youth Research, "The New Europe" and Global and Youth Culture. Childhood 8(2): 147166.

4. Lansdown G (2002) Youth Participation in Decision-making. Expert Meeting on Global Priorities for Youth, New York: United Nations Youth Unit.

5. Marx Karl (1959) Excerpt from "A Contribution to the Critique of Political Economy". In: Karl Marx, Friedrich Engels (Eds.)., Basic Writings on Politics and Philosophy, Garden City, New York.

6. Messkoub M (1992) Deprivation and Structural Adjustment. In: Wuyts M, Mackintosh M, Hewitt T (Eds.)., Development Policy and Public Action, Oxford: Oxford University Press, United Kingdom, pp.175-198.

7. (2011) Moolah, Asia, Internet Retrieval. 
8. Ogburn, William F (1964) On Culture and Social Change. In: Ogburn, William F (Eds.)., Chicago: University of Chicago Press, United States.

9. Thakur KT (2016) Mental. Neurological, and Substance Use Disorders: Disease Control Priorities. In: Thakur KT (Edt.)., ( $3^{\text {rd }}$ Edn.)., Washington DC, p. 4.

10. (1996) UNICEF, Fifty Years for Children.

11. (2002) United Nations, World Youth Report 2003, E/CN.5/2003/4, New York: United Nations Economic and Social Council.

\section{ISSN: 2574-1241}

DOI: 10.26717/BJSTR.2021.36.005797

Mohammad Taghi Sheykhi. Biomed J Sci \& Tech Res

(c) (P) This work is licensed under Creative

Submission Link: https://biomedres.us/submit-manuscript.php
12. (2020) World Population Data Sheet. Population Reference Bureau, Washington DC

13. (2020) World Health Organization.

14.Zis P (2019) Treatment of Neurological Manifestations of Gluten Sensitivity and Coeliac Disease, Springer Link. 21(3): 10.

$\begin{array}{ll}\text { BIOMEDICAL } & \text { Assets of Publishing with us } \\ \text { RESEARCHES } & \text { - Global archiving of articles } \\ \text { - Immediate, unrestricted online access } & \text { - Rigorous Peer Review Process } \\ & \text { - Authors Retain Copyrights } \\ & \end{array}$

